\title{
De Geest is geen scepticus; de hele Luther
}

\author{
W. van Vlastuin
}

\begin{abstract}
The contemporary 'turn to the subject' also involves a 'hermeneutical turn', which raises the question whether Scripture can still speak for itself. Arnold Huijgen proposes a return behind this development, by way of Luther, in order to hear the viva vox Christi again in Scripture. This essay argues that Huijgen does not do justice to the centrality of justification and the moral and historical claims of Scripture. It concludes that we can indeed learn from a retrieval of the viva vox, providing that we maintain the depth of the justification of the ungodly and the breadth of the moral and historical claims of Scripture.
\end{abstract}

\section{Inleiding}

Het is niets te veel gezegd dat het gezag van de Schrift in een crisis verkeert. ${ }^{1}$ Het gaat hierbij om - wat Kevin Vanhoozer genoemd heeft - de grootste uitdaging voor de gereformeerde theologie in een postmoderne cultuur. ${ }^{2}$ In deze crisis gaat het niet meer om de historische kritiek van de moderniteit, ${ }^{3}$ maar om de betekenis van de tekst. Het postmoderne alternatief brengt ons bij het ankerpunt van het enkele individu, ${ }^{4}$ de interpreterende gemeenschap, ${ }^{5}$ of de

1 W. Pannenberg, 'Die Krise des Schriftprinzips', in W. Pannenberg (red.), Grundfragen systematischer Theologie. Gesammelte Aufsätze, Göttingen, 1979, I:11-21.

2 K.J. Vanhoozer, 'Scripture and Tradition' in K.J. Vanhoozer, (red.), The Cambridge Companion to Postmodern Theology, Cambridge, 2003, 149-169, 157.

3 Vgl. J. Lauster, Prinzip und Methode. Die Transformation des protestantischen Schriftprinzips durch die historische Kritik von Schleiermacher bis zur Gegenwart, Tübingen, 2004. Karakteristiek is zijn conclusie dat de aandacht voor het menselijke karakter van de Schrift het transcendente karakter van de Schrift verzwakt, 447. B. van den Toren, Christian apologetics as cross-cultural dialogue, Londen, 2011, 11-12 wijst op het wankelende funderingsdenken in de postmoderniteit.

4 C. Taylor, A Secular Age, Cambridge, Mass./Londen, UK, 2007, 473-504 is illustratief. Vgl. M.D. Thompson, A Clear and Present Word. The Clarity of Scripture, Downers Grove, 2006, 32-45.

5 K.J. Vanhoozer, The Drama of Doctrine. A Canonical-Linguistic Approach to Christian Theology, Louisville, 2005, 3-16. 
contextbepalende interpretatie. ${ }^{6}$ Zo wordt de vraag naar onze hermeneutische methode opgeroepen: Kunnen we spreken over de eigen betekenis van de Schrift?? Wat betekenen de noties van de duidelijkheid en de genoegzaamheid van de Schrift. ${ }^{8}$

Arnold Huijgen heeft deze crisis goed aangevoeld en zo kwam hij tot Lezen en laten lezen. Hij geeft een analyse van Descartes' wending naar het subject die een objectivering van het niet-subjectieve met zich meebracht. ${ }^{9}$ Deze wending naar het subject heeft ingrijpende gevolgen gehad voor het gezag en het functioneren van de Schrift. ${ }^{10}$ De Schrift werd gereduceerd tot een neutraal en dood object waar wij met onze rationele instrumenten grip op kunnen krijgen en dat we gebruiken om ons te informeren of om ons gelijk te halen. Het gevolg hiervan is dat de Schrift een tandenloze tijger is waar geen mens nog iets van te duchten heeft.

Huijgen onderzoekt hoe een terugkeer achter Descartes eruitziet. Hij gaat daarvoor eerst te rade bij Luther. Hoe functioneerde de Schrift in Luthers theologie? Vervolgens analyseert hij de gevolgen van het perspectief dat Descartes ons aanreikt. In dat kader voert hij ook een pleidooi om onbevangen over de ziel te spreken, waarbij hij gebruikmaakt van concepten in Eckhart. Hij sluit dit af met een concretisering van het voorgaande in een drietal voorbeelden.

6 H.G. Gadamer, Wahrheit und Methode. Grundzüge einer philosophischen Hermeneutik, Tübingen, 1986.

7 Vgl. A.C. Thiselton, The Hermeneutics of Doctrine, Grand Rapids, 2007; J. Webster, 'Hermeneutics in Modern Theology: Some Doctrinal Reflections', in J. Webster (red.), Word and Church; Essays in Christian Dogmatics, Edinburgh, 2001, 47-86; C.J. White, (2014), 'Is it possible to discover 'the one' intended meaning of the biblical authors?' in Scottish Journal of Theology 67.2, 178-194; M. Wisse, 'Doing theology through reception studies: Towards a post-postmodern theological hermeneutics', in Nederduitse Gereformeerde Teologiese Tydskrif 53 (2012), 239-249.

8 J. Webster verstaat de duidelijkheid van de Schrift als een pneumatologische categorie, Holy Scripture. A Dogmatic Sketch, Cambridge, 2003, 93-95. Vgl. zijn Confessing God, London, 2005, 33-68. Vgl. A.T.B. McGowan, The Divine Spiration of Scripture, Nottingham, 2007, 28-29. M. Horton plaatst de leer van de Schrift als een formeel principe vooraan in zijn The Christian Faith. A Systematic Theology for Pilgrims on the Way, Grand Rapids, 2011, 35-219.

9 A. Huijgen, Lezen en laten lezen. Gelovig omgaan met de Bijbel, Utrecht, 2019, 114-126.

10 Vgl. W. van Vlastuin, Naar het hart van Jeruzalem. Over de betekenis van de geestelijke gemeenschap met Christus voor de prediking, Houten, 2012; Voor hart en hoofd. Een essay over Christus-identiteit in het onderwijs, Apeldoorn, 2019, 56-66. 
In deze bijdrage gaat het mij om het beroep op Maarten Luther. ${ }^{11}$ Er zijn twee aspecten in Luthers schriftleer die ik vergelijk met Huijgen. Dit leidt tot een conclusie.

\section{De rechtvaardigende viva vox}

Luthers schriftleer komt wellicht het meest pregnant tot uitdrukking in $D e$ Servo Arbitrio. Opvallend genoeg zette hij dit boek - door zichzelf beoordeeld als een van zijn beste boeken ${ }^{12}$ - in met de schriftleer. Deze inzet is om twee redenen opvallend. In de eerste plaats omdat de focus van dit boek ligt op de genadeleer. Blijkbaar zijn sola scriptura en sola gratia inhoudelijk niet van elkaar te isoleren in Luthers theologie. ${ }^{13}$ Het rechte verstaan van de Schrift is genade en als we genade ontvangen, dringt de boodschap van de Schrift tot ons door. Ten tweede is deze inzet opvallend, omdat Erasmus de kerk al eerder had opgeroepen om zich op de Schrift te oriënteren. Blijkbaar kon Erasmus' omgang met de Schrift Luther niet bekoren en scharnierde hier voor hem het uiteindelijke geding. ${ }^{14}$

Luthers Bijbel was geen neutraal object dat door het menselijk intellect wordt beheerst, maar het Woord beheerst ons. ${ }^{15}$ Het geheim hiervan was dat de Schrift voor hem geen abstractie was, maar hij hoorde hierin de viva vox

11 Vgl. voor het materiaal in dit artikel W. van Vlastuin, 'Sola scriptura: The relevance of Luther's use of Scripture in De Servo Arbitrio', in Hans Burger, Arnold Huijgen en Eric Peels (red.), Sola Scriptura: Biblical and Theological Perspectives on Scripture, Authority, and Hermeneutics, Leiden, 2018, 243-259.

12 WA (Weimarer Ausgabe) 8:99. Zie ook M. Brecht, Martin Luther, Stuttgart, 1986, 2:231. Brecht noemt dit werk een concentratie van Luthers werk.

13 Over de historische herkomst van de sola's, zie H. van den Belt, 'The Problematic Character of Sola Scriptura', Hans Burger, Arnold Huijgen en Eric Peels (red.), Sola Scriptura: Biblical and Theological Perspectives on Scripture, Authority, and Hermeneutics, Leiden, 2018, 38-55.

14 Luther behandelde de schriftleer ook al in Aan de christelijke adel van de Duitse natie (1520). Dit leidde tot verschillende debatten. Een goede inleiding in Luthers schriftleer biedt A. Beutel, 'Erfahrene Bibel. Verständnis und Gebrauch des verbum dei scriptum bei Luther', in A. Beutel (red.), Protestantische Konkretionen, Tübingen, 1998, 66-103. Vgl. ook zijn 'Wort Gottes' en 'Theologie als Schriftauslegung' in A. Beutel (red.), Luther Handbuch, Tübingen, 2005, 362-372, 444-450. Vgl. in deze bundel ook T. Kaufman, 'Luther und Erasmus', 142-152.

15 Het verstaan van de Schrift is een worsteling met zonde, dood en duivel, WA 45:559. Alleen in de weg van oratio, meditatio en tentatio verstaan wij de Schrift, WA 50:658-659, vgl. Thompson, A Sure Ground, 271-272; A. Beutel, 'Erfahrene Bibel', 86-88. 97-103; 'Theologie als Erfahrungswissenschaft' in zijn, Luther Handbuch, 454-459. 
van een persoonlijk God. ${ }^{16}$ Dit hing nauw samen met het christologisch gehalte van Gods Woord. ${ }^{17}$ Het ging hem ten diepste om Christus en het heil in Hem. ${ }^{18}$ Christus is dan ook inhoudelijk de sleutel om de Schrift te openen, terwijl we zonder de effectiviteit van de Geest totaal blind zijn voor deze eigenlijke boodschap van de Schrift. ${ }^{19}$

Ook als we door de Geest geleid worden, kunnen er voor ons grammaticale onduidelijkheden in het Woord zijn, ${ }^{20}$ maar de leer van het evangelie is ondubbelzinnig en duidelijk. Deze benadering had verstrekkende consequenties voor de uitleg van de Schrift. Als de uitleg van de Schrift niet afhankelijk is van menselijke interpretatiekaders, moeten we zeggen dat de Schrift voor zichzelf (scriptura sui ipsius interpres) spreekt. ${ }^{21}$ Dit inzicht maakte de reformator kritisch naar het gebruik van filosofie in de theologie. De thesen 43-44 van zijn Disputatio contra scholasticam theologiam (1517) leggen hier getuigenis van af, ${ }^{22}$ evenals these 29 in de Heidelbergse Disputatie (1518). ${ }^{23}$ Hetzelfde klinkt door in de vijftien thesen (1519) die het gebruik van de filosofie in de theologie verwerpen. ${ }^{24}$

Bij John Webster vinden we een actuele bezinning op de vraag wat dit betekent voor hermeneutiek. De interpretatie van Gods Woord is geen functie van kerk of theologie, maar omgekeerd. ${ }^{25}$ Omdat de leer van het evangelie niet van menselijke orde is, kan Gods transcendente spreken niet worden

16 WA 33:144. A. Beutel, 'Erfahrene Bibel', 71. Beutel licht toe dat Luther Deus loquens, verbum aeternum, verbum creatum, verbum scriptum en verbum praedicatum met elkaar verbindt, 'Wort Gottes'. Luther sprak niet over God, maar met God, B. Brock, Singing the Ethos of God, 166, 173. Het lezen van Gods Woord is het horen van Gods stem in het heden, Thompson, A Sure Ground, 55-59. Het karakter van viva vox verbleekt onbedoeld in Vanhoozers benadering, The Drama of Doctrine, 177, 229. Hoewel John M. Frame het propositionele karakter van de Schrift bepleit, erkent hij dat het primair Gods stem is, The Doctrine of the Word of God, Phillipsburg, 2010, 3-7.

17 De kern van de theologie draait om de ontmoeting van God en mens, WA 40.II:328. Vgl. B. Lohse, Luthers Theologie, 48-49, 53, 204.

18 WA 18:606; WA 8:236, 239.

19 WA 18:609. Het is een wonder als twee of drie mensen niet blind zijn voor het getuigenis van de Schrift, WA 18:659.

20 WA 18:606; WA 18:661; WA 18:653-658; WA 20:728.

21 WA 7:97; 10.III:237. Luther verwierp regels en normen voor de uitleg van de Schrift, WA 7:9.

22 WA 1:224-228.

23 WA 1:365; Vgl. WA Br 1:170; WA Br. 2, no. 321:157.

24 WA 6:28-29.

25 Vgl. J. Webster, Holy Scripture, 49, 107-135; A. Beutel, 'Erfahrene Bibel', 67. 
opgesloten in een menselijk interpretatiekader. Dit is een fundamenteel inzicht voor hermeneutiek. Hermeneutiek kan niet verzelfstandigd worden ten opzichte van de Schrift, maar ze wordt bepaald door de Schrift. ${ }^{26}$ Zelfs de uitlegger heeft geen zelfstandigheid ten opzichte van de Schrift. ${ }^{27}$

Deze reserve van Luther en Webster tegenover filosofische concepten is herkenbaar in Huijgens pleidooi om zich te laten lezen door de Schrift. Evenals de reformator is hij er beducht voor dat de Schrift wordt opgesloten in het systeem van een menselijk interpretatiekader. Voordat mensen Gods stem onderbreken, moeten we God in zijn Woord geheel laten uitspreken.

Tal van noties die Huijgen aansnijdt in zijn behandeling van Luthers schriftleer, onderstrepen het existentiële karakter van het luisteren naar het Woord. Vooral de notie dat Gods spreken in de Schrift tegenwoordige tijd is ${ }^{28}$ en geladen is met de presentie van de Heilige Geest. ${ }^{29}$ Nauw hieraan verbonden is het inzicht dat we de Schrift niet op een neutrale manier kunnen lezen, maar dat we altijd voor Gods aangezicht staan. ${ }^{30}$ Daarom is er ook een nauwe relatie tussen de rechtvaardigingsleer en de schriftleer. Het verstaan van de Schrift betekent dan ook niet dat wij zeggen dat we het snappen, maar dat we sterven en verdoemd worden. ${ }^{31}$

In een actuele toepassing van Luthers theologie verwacht ik deze ontmoeting van de verloren mens en de rechtvaardigende God. Hier scharniert het immers om in de ware theologie. ${ }^{32}$ Luther heeft het over het geding met duivel, zonde en dood: 'Tot de leer van het geloof behoort in de eerste plaats dat wij weten wat zonde, wet en dood is, en wat de zonde werkt.' ${ }^{33}$ Daarom moeten zondaren eerst tot verootmoediging en vertwijfeling worden gebracht voordat het evangelie ons kan troosten. Het omgekeerde is ook waar. Zonder deze heil-

26 Volgens J. Webster ontbreekt het discipelschap te vaak in de hermeneutiek, Holy Scripture, 92. K.J. Vanhoozer stelt dat de canon het interpretatiekader is voor het verstaan van God, de wereld en onszelf, The Drama of Doctrine, 149. Vgl. ook Brian Brock, Singing the Ethos of God, 264-265, 268-269.

27 J. Webster, Holy Scripture, 55-56; Thompson, A Clear and Present Word, 54. Webster is kritisch over elke formele claim ten aanzien van de Schrift, 55-56, 93. Het spreken over de eigenschappen van de tekst acht hij deïsme, 36. Vgl. Thompson voor kritiek, A Clear and Present Word, 73-79.

28 Huijgen, Lezen en laten lezen, 42, 44, 46.

29 Huijgen, Lezen en laten lezen, 28.

30 Huijgen, Lezen en laten lezen, 71-72.

31 Huijgen, Lezen en laten lezen, 69-70.

32 Zie Huijgens verwijzing naar Luthers opmerking bij Psalm 51, Lezen en laten lezen, 77.

33 WA 51:123. 
zame wanhoop blijft het evangelie voor ons gesloten. ${ }^{34}$ Daarom roept hij zondaren op om zich te laten onderwijzen door Gods wet als zij geen besef hebben van hun zonden en ellenden. ${ }^{35}$ We zouden dus kunnen zeggen dat het zich laten lezen door de Schrift bij Luther op de noemer gebracht kan worden van het zich laten lezen door de wet en zich laten lezen door het evangelie. Dit alles is voor Luther geen woordenspel, maar het gaat om de troost in de uiterste nood. Het evangelie troost degenen die door hun zonden bevreesd en beangst worden en hun die in de hel worden gevoerd, wordt de hemel beloofd. ${ }^{36}$

In dit licht vraag ik mij af waar Luther in het slothoofdstuk van Lezen en laten lezen is gebleven. Huijgen behandelt in het slothoofdstuk drie voorstellen, namelijk van Bonhoeffer, Noordmans en een eigen exegese. Bonhoeffers behandeling van Psalm 58 reikt ons leeswijzers aan bij de omgang met wraakpsalmen, in deze behandeling wordt eenmaal gezegd dat deze psalm ons schuldig stelt, maar dat lijkt mij een andere golflengte dan wat we over Luther hebben meegekregen. Noordmans' trinitarische verstaan van de heilsgeschiedenis biedt waardevolle gezichtspunten, maar het neigt ook naar een hermeneutische methode in plaats van het heilsordelijke gelezen worden door de Schrift met de persoonlijke rechtvaardiging als centrum. Iets dergelijks geldt van Huijgens eigen experimentele exegese van 1 Petrus 3:1-7.

Dit maakt het beroep op Luther problematisch. Ik begrijp dat er een beroep wordt gedaan op Luthers existentiële en christologische lezing van de Schrift, maar in de toespitsing van het boek verbleekt deze spits. Daardoor krijgen Luthers woorden iets gemoedelijks en speels, terwijl Luther ze heeft bedoeld vanuit de meest ultieme ernst. Kan er zo sprake zijn van een beroep op Luther? Als we het meest eigene van Luther niet laten functioneren, wat is dan de betekenis van het beroep op de reformator? Is dit geen postmodern eclectisch gebruik van de reformator?

Dit raakt ook aan het gereformeerde belijden. In antwoord 89 van de Heidelbergse Catechismus gaat het om de levenslange afsterving van de oude mens die blijkt in het voortgaande berouw over onze zonden die God tot toorn brengen. Het instrument van de levende Christus om ons in zijn sterven te betrekken is volgens antwoord 115 van deze catechismus de scherpe prediking van Gods wet. In deze kaders blijft de rechtvaardiging van de goddeloze het artikel waarom ons luisteren naar de viva vox Christi draait. In het kader van de problematiek die in dit nummer aan de orde wordt gesteld, 
meen ik dat de hermeneutische sleutel die Luther ons aanreikt, en die in de gereformeerde traditie is herkend als wettige sleutel om het Woord te openen, wezenlijk is om de levende stem van Christus in zijn Woord te horen.

\section{Belijdenis van de leer}

Luther botste ook met Erasmus omdat deze weinig bevrediging vond in belijdende en bindende uitspraken. Luther reageerde heftig vanuit zijn overtuiging dat de geest van het scepticisme niet de geest van het christelijk geloof is. ${ }^{37}$ Het christelijk geloof verheugt zich juist in stellige en belijdende uitspraken. Het begrip doctrina is voor Luther geen intellectualistisch en rationalistisch begrip, omdat het functioneert in het kader van de viva vox.

Luther verdedigde daarom ook dat alle waarheden in de Schrift gepreekt moesten worden, omdat de waarheid zeldzaam is. ${ }^{38}$ Het weglaten van waarheid zou betekenen dat de christelijke leer niet meer waard is dan de visie van filosofen. ${ }^{39}$ De hele waarheid moet aan de orde komen al zou de hele wereld in opstand komen. ${ }^{40}$ Het feit dat Luther deze opmerking in de Boerenoorlog maakte, ${ }^{41}$ laat wel zien hoezeer hij dit meende.

Dit roept de vraag op wat Luther precies met de doctrina bedoelde. Bedoelde hij alleen de leer van Christus, de boodschap van de verlossing met een toespitsing naar de rechtvaardiging? Gaat het hier ook om de scheppingsleer, de historische zondeval en de leer van het huwelijk? Wat betekenen de tweerijkenleer en de kruistheologie van Luther in dit verband?

Het blijkt dat de soteriologische concentratie voor Luther geen reductie was. Het geding met Erasmus voerde hij om de kwestie van de vrije wil. Als zodanig was dit geen thema dat in het klassieke christelijke credo werd benoemd, maar voor Luther ging het hier om de mogelijkheden van de mens in de confrontatie van God en mens. Daarom behoorde het voor hem tot de kern van het evangelie.

Er zijn ook andere momenten waar blijkt dat Luther de leer niet smal soteriologisch uitlegde. Wie zijn commentaren op Genesis leest, ontdekt dat de reformator oog had voor de rijkdom van de werkelijkheid van de schepping

37 WA 18:603.

38 Slechts twaalf apostelen accepteerden de waarheid en slechts vijf bisschoppen ten tijde van Arius, WA 18:649-652.

39 WA 18:605;930. Erasmus denkt te menselijk over God, WA 18:622.

40 WA 18:625, 627-628. Vgl. A. Beutel, 'Erfahrene Bibel', 94.

41 M. Brecht, Martin Luther 2:172-193; H. Schilling, Martin Luther. Rebell in einer Zeit des Umbruchs. Eine Biographie, München, 2012, 294-317. Zie ook R. Marius, Martin Luther, 397-403. 
zonder deze te bezien vanuit een reductionistische aristotelische bril. Ondanks het grote gezag van Augustinus weersprak hij hem ten aanzien van de schepping in zes dagen. ${ }^{42}$ Luther ging het geding met de kerkvader ook aan ten aanzien van huwelijk en seksualiteit. ${ }^{43}$ Augustinus zag seksualiteit als een noodzakelijk kwaad om een nageslacht te verwekken. De seksuele gemeenschap diende dan ook zonder hartstocht plaats te hebben. Luther brak met Augustinus en de christelijke traditie voor hem omdat hij de door God gegeven orde van het huwelijk in de schepping aanvaardde. Hij kwam niet alleen ten aanzien van de rechtvaardigingsleer tot een kritische opstelling ten aanzien van de traditie, maar ook in zijn benadering van huwelijk en seksualiteit. Dat bracht hij op een sprankelende manier onder woorden: 'Daarom, ben je een vrouwtje of een mannetje en ben je vruchtbaar, grijp maar fris en vrolijk naar het huwelijk, op het woord van God, die deze stand heeft gezegend. '44

Deze uitspraak laat zien dat het Woord van God ook ten aanzien van huwelijk en seksualiteit voor Luther leidend was. Luthers eigen huwelijk was symptomatisch voor het gezag van Gods Woord. Daarin kwam uit dat het ene woord van God 'Het is niet goed dat de mens alleen zij' meer waard was dan honderdduizend woorden van engelen over het huwelijk of het celibaat. In de context van zijn tijd was dit een buitengewoon geladen interpretatie van Gods Woord.

Deze kleine verkenning van Luthers omgang met de Schrift brengt aan het licht dat zijn existentiële omgang met de Schrift niet werd beperkt tot de relatie tussen God en mens. Voor Luther bood de Schrift ook gezaghebbende historie, gezaghebbende orde en gezaghebbende moraal. Bij Luther is er geen sprake van reductie van de inhoud van de Schrift naar de existentiële relatie, maar de gehele Schrift heeft gezag voor ieder mens en door de Geest heeft het Woord een existentieel effect in de gelovige. De Schrift is niet alleen een tegenover in de rechtvaardiging, maar ook in de moraal en de ethiek.

Daarom denk ik dat Huijgen het schriftgezag te veel beperkt door dit alleen te betrekken op de relatie tussen Christus en de gelovigen. Dit zou een postmoderne insteek kunnen zijn. Hij noemt zijn boek een 'mini-hermeneutiek', maar hij geeft geen hermeneutische opening naar hot issues als homoseksualiteit, de vrouw in het ambt en het vraagstuk van de schepping. Luther

42 WA 42:5. Ook de historische zondeval is voor Luther van belang. Er is een absolute breuk tussen de zondeloze Adam en de gevallen mens, WA 42:79-83. Deze breuk raakt ook onze fysieke situatie, WA 42:46, 76.

43 Vgl. H.W. de Knijff, Venus aan de leiband. Europa's erotische cultuur en christelijke sexuele ethiek, Kampen, 1987, 102-117.

44 WA 24:55. 
zou geen schroom hebben gehad om zich hierover uit te laten met 'stellige en bindende uitspraken'.

\section{Tot slot}

Kortom: het beroep op Luther geeft de mogelijkheid om een spade dieper te spitten in de existentiële omgang tussen Christus en de gelovige enerzijds, terwijl het beroep op Luther anderzijds een kader aanreikt om het schriftgezag ook breder te laten functioneren in historische en morele zin. Dit laatste brengt mij tot de probleemstelling aan het begin van deze bijdrage. Huijgen levert terecht kritiek op de object-subjectscheiding in Descartes en hij vindt terecht in Luther een krachtige metgezel om dit object-subject-denken te doorbreken. Als dit beroep op Luther in de toepassing echter niet wordt verdiept tot de doorleving van de rechtvaardiging van de goddeloze enerzijds en als het anderzijds wordt versmald tot de relatie zou de postmoderne relativering weleens schadelijker kunnen zijn dan de moderne objectivering.

Positief geformuleerd: Luther is een goede leermeester om de viva vox Christi opnieuw te horen in de Schrift. Daarbij dienen we de blijvende diepte van de rechtvaardiging van de goddeloze te honoreren en ons te laten gezeggen door de breedte van de historische en morele claim van de Schrift.

W. van Vlastuin is hoogleraar 'Theology and Spirituality of Reformed Protestantism' aan de Vrije Universiteit Amsterdam. 